\title{
Educational technology on expressing breast milk: development and validation of a Serious Game
}

Vanessa Correa de Moraes 1

iD https://orcid.org/0000-0002-5792-3514

Lucimare Ferraz 2

iD https://orcid.org/0000-0002-2487-8614 1,2 Programa de Pós-Graduaçãoem Enfermagem na Atenção Primária à Saúde. Universidade do Estado de Santa Catarina, Rua Sete de Setembro, 91 D, Chapecó. Santa
Catarina, SC, Brasil, CEP: 89.806-152. E-mail: vanecm.10@hotmail.com

\begin{abstract}
Objectives: to develop and validate a Serious Game about expressing breast milk for occupational nurses working in agribusiness companies.

Method: methodological study, carried out in three stages: construction, evaluation and validation of the Serious Game. This study was carried out in 2020, included nine nurses from an agribusiness company and nine specialists in obstetrics and health worker.

Results: the game was structured in four phases: preparation for expressing milk (previous general care needed for expressing milk); methods for expressing milk (techniques to express milk); storage (care related to containers and temperature); the use of breast milk (transport, thawing method, and provision to the child). The content was validated by experts, obtaining an overall Índice de Validade de Conteúdo(Content Validity Index) of $86.72 \%$. The game was tested by occupational nurses, and its "usability" was validated by the System Usability Scale instrument, with an index of $83.89 \%$, and the "knowledge improvement" by the EGameFlow instrument with a mean of 6.52 .

Conclusion: the Expressing Milk Game technology obtained a high level of validity in terms of content and usability, demonstrating that it is an educational technology for health professionals to guide the maintenance of breastfeeding to nursing mothers.
\end{abstract}

Key words Educational technology, Breastfeeding, Nursing

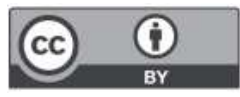




\section{Introduction}

Breastfeeding (BF) contributes to a healthier and more environmentally sustainable universe, promoting countless benefits for the mother and child, being the ideal food for the child's growth and development.1-3 Despite its proven benefits, degrowth of this practice, especially exclusive breastfeeding until the child is six months old, is closely linked to the insertion of women in the working environment, For this reason, healthcare for the working mother and the adequacy of her work environment are essential. 4

From this perspective, it is important for the nursing mother, especially when returning to work, have guidance on the importance and maintenance of breastfeeding, as well as the practice of expressing milk during the working day. 5 However, based on observations from one of the researchers in this study who works as a nurse in an agroindustry, nurses need to be trained in regard to the care to provide by expressing milk for nursing mothers. Fellow nurses said they did not feel capable and confident to promote/guide puerperal women on their return to work. Several times these women faced situations such as mastitis, fissures, and had numerous doubts about expressing milk, storage and provision of the breast milk

Thus, an effective teaching and learning process is essential for the qualification of health professionals who work with nursing mothers. 6 Serious Game (SG) represent a strategy capable of promoting teaching-learning. This is a technology characterized by the ability to disseminate knowledge digitally, transforming educational paradigms and standing out among other conventional teachinglearning methods. ${ }^{7}$

The educational technology of Serious Game, developed through software and specific interactivity tools, has as its main focus to develop teaching-learning strategies to stimulate clinical reasoning and decision-making, especially in the area of Medicine and Nursing. ${ }^{6}$

Considering the numerous advantages for the learning process and health education that the Serious Game makes possible, a study was carried out with the aim of developing and validating a Serious Game on expressing breast milk for occupational nurses working in agribusiness companies.

\section{Methods}

This is a methodological study in which an educational technology of the Serious Game type was developed and validated. The product was developed in three stages, namely: construction and validation of the educational content; development of the Serious Game; and validation with the target audience.

The first stage consisted in the construction of the content regarding the care and practices of expressing breast milk. To this end, scientific evidence was sought in the SciELO, PubMed and Scopus databases, in addition to manuals from the Ministry of Health, technical notes and documents from the Rede Brasileira e Global de Banco de Leite Humano (Brazilian and Global Human Milk Bank Network).

The content was organized in four topics in order to describe the process of the preparation for expressing milk, expressing milk itself and its storage and provision of breast milk. At first, the necessary care is addressed before starting expressing milk, especially regarding to hygiene. Secondly, the methods/techniques recommended to begin expressing milk and the possible complications in case of inadequate procedure are described guidelines that facilitate expressing milk Thirdly, the storage, care with the identification, sizes and cleaning of the collecting bottles are portrayed processes to ensure quality storage, temperature and recommended time for refrigeration and freezing. Fourth, guidelines are provided on the use of breast milk, detailing issues on transport, ideal form of thawing, and care during provision to the child.

Initially, the educational content was organized in the Power Point ${ }^{\circledR}$ software, totaling 29 slides. Each slide contained one of the questions of the gamewith corresponding alternativeanswers.

For validation content, the participation of professionals who were part of the research groups with expertise in the area of breastfeeding was sought. A search was carried out in the Diretório dos Grupos de Pesquisa do Conselho Nacional de Desenvolvimento Científico e Tecnológico (CNPq), (Directory of Research Groups of the National Council for Scientific and Technological Development), considering the search term "breastfeeding". Thirty-nine groups were identified; however, for this study, we chose to select those specific to the area of nursing. Thus, 12 groups were selected; however, it was found that three had not been updated for more than 12 months, so only nine were selected.

The first strategy for the specialists was to search and contact the leaders of the research groups, but the expected return was not obtained, for not reaching the number of six researchers as recom- 
mended by the authors, Polit and Beck. ${ }^{8}$ Therefore, contacts were made with regional/local specialists with expertise in the area of breastfeeding and healthworker, with doctoral academic training.

The invitation to participate in the study was made via email and the instruments for data collection were made available via Google Forms ${ }^{\circledR}$. Nine experts returned to content the evaluation, two researchers from the research groups and seven regional experts.

After accepting to participate in the research, the experts received a questionnaire with the following questions: sex, academic background, time since graduation, place of work, area of operation, contact with digital games, and use of digital games as educational tool. These data were analyzed using descriptive statistics with calculation of relative frequency and median.

Next, two instruments related to validation content were sent: the first consisted of 14 questions with content related to the preparation and methods of expressing milk, and the second consisted of 15 questions about storage and supply of expressed milk. The instrument used for validation content was the Validade de Conteúdo (IVC) (Validity Content Index), which allows the experts to check the agreement on a given topic. ${ }^{9}$ In this context, each slide/screen (question and answers) was evaluated using a Likert type scale, in which each item represented a score from 1 (one) to 4 (four), being: $1=$ totally adequate; $2=$ adequate; $3=$ partially adequate; $4=$ inadequate. The score was calculated by the sum of agreement of the items evaluated with 1 and 2, and the items evaluated with a score of 3 and 4 were revised. To be considered valid, each item had to present a IVC greater than or equal to $0.78 \%$, so the items that presented a lower result were changed.

The second stage of the study dealt with the development of the educational technology called Expressing Milk Game, which was elaborated in six phases: concept; pre-production; production; alpha, beta and gold phase. 10

The creation of a Serious Game in the health area requires mastering the content, as well as other areas that involve the process, such as knowledge about technologies and design. It is necessary for the team to be multidisciplinary in order to minimize the risks of launching products that do not meet educational and technological expectationsl.6 From this perspective, a multidisciplinary team was formed to develop the Serious Game, with professionals from the field of nursing (responsible for educational content), information technology (programming), and design (interfaces).
Thus, the Serious Game was developed in the following steps: concept; pre-production; production; alpha, beta and gold phase. After the team defined the concept and pre-production elements, the first version of the game was developed (production phase); then, this version was tested and evaluated by the target audience - nurses (alpha phase), and the items identified as needing improvement were passed on to the programming team for adjustments, and the second version of the game was developed (beta phase). The conclusions were carried out so that the game could be implemented with the nursing staff (gold phase)of the company. The production of the Expressing Milk Game lasted five months until the version presented to be evaluated by nurses working in the agribusiness company.

The initial sketch of the game was made by the master's student in nursing, who organized the "screens" in Power Point ${ }^{\circledR}$ to present the idea to the other team members. With knowledge of the material developed, the professional designer developed the first version of the game interfaces, which went through a process of validation and adjustments after suggestions from the master's student and advisor. The version of the interfaces and content was passed on to IT professionals for programming. This stage of development lasted five months (November 2019 to March 2020). During this time, several adjustments were made to the product related to the content, layout and design. These alignments were made in team meetings in order to prepare the best version to be tested by the target audience.

The third stage involved the validation of the Serious Game with the target audience. All the 14 occupational nurses who work in a large agribusiness company with branches in the States of Santa Catarina, Rio Grande do Sul, Paraná and Mato Grosso were invited to participate in this stage. Thus, the criterion for inclusion was to be a nurse working in the agribusiness company, the focus of this work was regardless of the length of experience and sector (work or corporate health). As an exclusion criterion, nurses away from their activities due to illness or accident, vacation or maternity leave at the time of data collection were excluded.

At the time of the study, all were able to participate. They were invited via email, with the link to access the game and the data collection instruments that were made available via Google Forms ${ }^{\circledR}$. Nine nurses sent the evaluation of the SG. The others justified that they were at the forefront in actions to prevent the Coronavirus pandemic (COVID-19) and had no time at that moment for a careful evaluation of the game. Considering the number of eight evalu- 
ators recommended by the Associação Brasileira de Normas Técnicas (ABNT) ${ }^{8}$ (Brazilian Association of Technical Standards), a total of nine nurses was considered sufficient to validate the technology.

Along with the link to access the game, an instrument was sent to characterize the target audience with questions about sex, age, time of experience, time of work in the agribusiness sector, contact with digital games and use of digital games as an educational tool. The instrument was analyzed through descriptive statistics to calculate the relative and median frequency.

Two instruments were used to evaluate the Expressing Milk Game. The System Usability Scale (SUS) instrument was used to measure usability, which is considered an easy-to-understand tool that takes into account the opinion of users, evaluating the satisfaction of the target audience. 11 The questions were graded on a Likert-type scale, with values from 1 to 5, classified respectively as (1) "I strongly disagree", (2) "I disagree", (3) "I neither agree nor disagree", (4) "I agree" and (5) "I strongly agree".

To calculate the index, first, the sum of the score of each item was performed (score from 1 to 5). For the odd questions, the individual score was the grade received minus 1 . For the even questions, the contribution was 5 minus the grade received. After this process, the sum of all the scores was multiplied by 2.512, thus obtaining results between 13 and 20.5 (Worst possible); 21 to 38.5 (Poor); 39 to 52.5 (Medium); 53 to 73.5 (Good); 74 to 85.5 (Excellent); and 86 to 100 (Best possible). ${ }^{1}$

In order to assess the satisfaction/learning of the Serious Game, the instrument EGameFlow, "Knowledge Improvement" consisting of five questions, was used, which is validated and has been applied in other games. 13 The questions were graded on a Likert-type scale, with values from 1 to 7 , according to experience with the game, with 1 being "it does not meet the objective" and 7 "it meets the objective with excellence". The final evaluation of the category was based on the arithmetic mean of the items. In addition to the SUS and EGameFlow instruments, the following question was included: "Do you have any criticism and/or suggestions about the product?".

It is noteworthy that there was no sample calculation for the professional nurses participanting in the study, since all (100\%) who worked in the agribusiness company in question were selected for the study. As for the experts, there were nine participants, following the recommendation of the Associação Brasileira de Normas Técnicas (ABNT/ISO/IEC 25062:201) (Brazilian Association of Technical Standards), which indicates at least eight evaluators are needed to validate the software. 8 The present study was approved by the Ethics Committee for Research Involving Human Beings of the Universidade do Estado de Santa CatarinaCEPSH/UDESC under the opinion number 3.670.919. To use the "EGameFlow" instrument translated and validated by the Learning Objects Laboratory (LOA), authorization was requested via e-mail. All participants declared consent on the Informed Consent Term sent via e-mail.

\section{Results}

In the validation content, $66.7 \%$ of the specialists worked in the area of women's health/obstetrics and $33.3 \%$ in the area of occupational health. Among the professionals, eight worked in a higher education and one in teaching and care. The median time of graduation was 20 years. All experts answered that they considered the use of digital games as an interesting educational tool, but $50 \%$ rarely used this technology and $50 \%$ used it on a monthly basis. As for the preferred device of use, $88.88 \%$ opted for cell phones and $11.11 \%$ for computers. The validity content index of the consulted experts is shown in Table 1.

The overall IVC content evaluated was $86.72 \%$. Although the IVC was high and considered validated, the team analyzed the experts' suggestions and changed the questions with a change rate greater than $0.78 \%$. The changes made are described in Table 2, making it possible to see how the version sent for evaluation was and how it looked after the suggestions and changes made by the researchers.

The experts also suggested the inclusion of two questions in the Expressing Milk Game. One of them was added to the second phase, addressing the importance of guiding the nursing mother that the collected milk is usually little (volume) in relation to what the baby drinks. The other question was in the third phase, about the size of the collecting bottles, that need to be small to avoid waste. It is noteworthy that the textual script was adapted and corrected by a professional with a degree in Linguistics.

After making the changes suggested by the experts and professionals, the game was structured with the contents distributed as follows: in the first phase, four questions about the preparation for expressing milk; in the second phase, eleven questions about theexpressing milk technique; in the third phase, eight questions about storage; and in the fourth phase, eight questions about the transport of milk after the collecting thawing method, and provi- 


\begin{tabular}{|c|c|c|c|c|c|}
\hline \multirow[t]{2}{*}{ Phases } & \multirow[t]{2}{*}{ Questions } & \multirow[t]{2}{*}{ IVC \% } & \multicolumn{3}{|c|}{ Experts' suggestion } \\
\hline & & & I accept & I partially accept & I do not accept \\
\hline \multicolumn{6}{|l|}{ 1st Phase - Preparation for } \\
\hline \multirow[t]{4}{*}{ expressing milk } & 1 & 77.8 & $x$ & & \\
\hline & 2 & 77.7 & $x$ & & \\
\hline & 3 & 88.9 & & & $\mathrm{x}$ \\
\hline & 4 & 77.8 & $x$ & & \\
\hline \multicolumn{6}{|l|}{ 2nd Phase } \\
\hline \multicolumn{6}{|l|}{ Method / technique for } \\
\hline \multirow[t]{10}{*}{ expressing breast milk } & 5 & 88.8 & $x$ & & \\
\hline & 6 & 77.8 & & & \\
\hline & 7 & 100.0 & & $\mathrm{x}$ & \\
\hline & 8 & 100.0 & & $\mathrm{x}$ & \\
\hline & 9 & 77.8 & & & $x$ \\
\hline & 10 & 88.9 & $x$ & & \\
\hline & 11 & 66.7 & & $\mathrm{x}$ & \\
\hline & 12 & 88.9 & & & $x$ \\
\hline & 13 & 88.8 & & $x$ & \\
\hline & 14 & 77.8 & & & $x$ \\
\hline \multicolumn{6}{|l|}{ 3rd Phase - Storage of the } \\
\hline expressed breast milk & 15 & 87.5 & & & \\
\hline \multirow[t]{6}{*}{ collected } & 16 & 87.5 & & & $x$ \\
\hline & 17 & 50.0 & & $\mathrm{x}$ & \\
\hline & 18 & 74.7 & & $x$ & \\
\hline & 19 & 100.0 & & & \\
\hline & 20 & 87.5 & & & \\
\hline & 21 & 87.5 & & & $x$ \\
\hline \multicolumn{6}{|l|}{ 4th Phase - } \\
\hline \multicolumn{6}{|l|}{ Provision of the expressed } \\
\hline \multirow[t]{8}{*}{ breast milk to the child } & 22 & 100.0 & & & \\
\hline & 23 & 100.0 & $\mathrm{x}$ & & \\
\hline & 24 & 100.0 & $x$ & & \\
\hline & 25 & 75.0 & & & $x$ \\
\hline & 26 & 100.0 & $x$ & & \\
\hline & 27 & 100.0 & & & \\
\hline & 28 & 100.0 & & & \\
\hline & 29 & 87.5 & & & \\
\hline
\end{tabular}

sion to the child.

The Expressing Milk Game was built in the form of a quiz, in the point-and-click genre (the player defines the action he will take -"point"; screen location - "click") and was developed to work on the Android platform to be used in cell phones. It is in 2D format and we chose to use the Unit tool, due to the flexibility in working with games of this format.

During the game, the health professionals must answer the questions by clicking on the answer alternative that they judge to be correct. Whenever the players get the question right, they are rewarded with points ( 1 st phase questions: for each correct answer, 20 points; $2^{\text {nd }}$ phase: 40 points; $3^{\text {rd }}$ phase: 60 points; and 4 th phase: 80 points). When the incorrect answer is selected, the player "loses a life" and the avatar appears with a facial expression of sadness/disappointment, with an observation of correction, and also, to relax the moment of the failure, local speeches/sayings of the South region were adapted, like "mas bah; que barbaridade..." "but hey!; what a shame...." When reaching the end of the game, the 
Table 2

Demonstration of the changes made on the Expressing Milk Game after experts' evaluation, 2020.

Question Game in the evaluated version $\quad$ Game final version

To cover hair, use mask, the washing of breasts To cover hair, use mask, wash hands and wash breasts. and washing of hands.

Adornments like watches, bracelets, rings and Adornments such as watches, bracelets, rings, nonproducts that can set off smells like perfumes and intact nail polish and products that can set off smells creams. such as perfumes and creams.

The practice of expressing milk can be performed The practice of expressing milk can be performed: (the through: word through was removed from the question).

The thumb must be positioned at the upper edge The thumb must be positioned at the upper edge of of the areola and the index finger at the lower the areola and the index and the middle fingers at the edge, supporting the breast with the other fin- lower edge (supporting the breast with the other fingers. gers was removed) backwards, toward the chest.

In circular movements, in the nipple-areolar In circular movements, with the fingertips in the nippleregion, with your fingertips, massage with your areolar direction, on painful areas, massage should be hands, and the rest of the breast, in painful areas, intensified, moving the breast in a forward-tilting posimassage should be intensified, moving the breast tion can be encouraged (the word region and massage in a forward-inclined position can be encouraged. with your hands, and the rest of the breast were removed).

Correct, as it contributes to a reduction of up to Correct and incorrect answer optional (as it contributes $90 \%$ of the bacterial population; incorrect, as dis- to a reduction of up to $90 \%$ of the bacterial populacarding milk does not reduce bacterial population tion; incorrect, as discarding milk does not reduce bacterial population were removed).

Which guidelines are important to stimulate oxy- To stimulate the production of oxytocin, it is important tocin; getting comfortable and relaxed, thinking to guide the nursing mother about; water intake, propabout the baby, making gentle massages er nutrition, staying comfortable and relaxed, thinking about the baby and making gentle massages (beginning of the sentence, which guidelines are important, was removed).

Having adequate containers, the expressing milk Maintaining hygiene throughout the expressing milk process must be adequate, following the guide- process; having suitable containers; milk must not be lines regarding hygiene, it must be stored in a suit- filled to the top of the bottle; suitable storage location able place, not necessarily a place only for this pur- and temperature (organized in the order of presentapose, maintaining adequate temperature. tion and for this purpose only was removed).

Previous washing of the bottle with soap and Previously wash with soap and water, boil the lid and water, it is recommended to boil the lid and let it the bottle for 15 minutes and let it dry on a clean cloth. dry on a clean cloth. 
Demonstration of the changes made on the Expressing Milk Game after experts' evaluation, 2020.

\begin{tabular}{lll}
\hline Question & \multicolumn{1}{c}{ Game in the evaluated version } & \multicolumn{1}{c}{ Game final version } \\
\hline 23 & $\begin{array}{l}\text { Expressing milk (which has been refrigerated) } \\
\text { must be transported home by the nursing mother milk (which has been refrigerated) must be } \\
\text { at a temperature of }\end{array}$ & $\begin{array}{l}\text { transported home by the nursing mother at a maxi- } \\
\text { mum temperature of_- (the word expressing was } \\
\text { removed). }\end{array}$
\end{tabular}
perature of ature of__(the word expressing was removed).

player saves the score in the ranking. In Figure 1, it is possible to observe the game interfaces.

The validation with the target audience was carried out in two aspects: "Usability" and "Improvement of knowledge". Nine occupational nurses participated in this stage, all women, ranging from 27 to 52 years old, with a median of 33 years. The mean length of time working as an occupational nurse in the agribusiness company was 9.7 years Regarding to the use of games as an educational tool, $88.9 \%$ thought it was important and $11.1 \%$ still had no opinion. As for contact with games, $66.7 \%$ played them rarely, $22.2 \%$ weekly and $11.1 \%$ monthly. All of them said they prefferred playing on cell phones.

Regarding the usability of the Expressing Milk Game, evaluated by health professionals, the mean obtained was $83.89 \%$, classified as excellent, as can be seen in Table 3. Only one nurse indicated that usability could be improved and the suggestion was to offer the possibility of accessing the questions that had already been answered.

Regarding the evaluation of the category "Improvement of knowledge" by the EGameFlow (Tsuda et al.14) instrument, which contains a Likert scale from 1 (It does not meet the goal of catching the attention) to 7 (It meets the goal of calling the attention with excellence), it was seen that the final score had a mean of 6.52 , as shown in Table 4. This result shows that the nurses considered that the Serious Game improved their knowledge about expressing breast milk.

At the end of the evaluation of the Expressing Milk Game, the nurses answered the question, expressing a fruitful experience with the educational technology: "Excellent tool"; "Very good game! Congratulations"; "I learned a lot from this game, it was a great experience".

Given the positive results, the Expressing Milk Game was implemented in the agribusiness company as a continuing educational program, being made available to all health professionals and is in the process of being made available on PlayStore. Likewise, readers of this article who are interested in having/knowing the game, just request the link by email: ordenhagame@gmail.com. It is also noteworthy that there is no conflict of interest among researchers, academic and the agribusiness company.

\section{Discussion}

The Expressing Milk Game was considered an adequate technology by the experts, since theIVC obtained a value of $86.72 \%$, considered fully satisfactory according to a study of educational technologies. 15 The content validation process is extremely important, 16 for this reason, the questions that reached a lower IVC were readjusted. Thus, this procedure adopted was enriching and essential for the improvement and qualification of the Serious Game.

It is of paramount importance that educational technologies contain truthful content, based on scientific knowledge, in order to increase credibility and demonstrate commitment to the knowledge development process. 17 In addition to the need for scientific content, it is essential to adapt the evidence for the local context so that there is the translation of knowledge between researcher and user. 18 The traditional methodologies used for this purpose need to be innovative and the use of games can be an alternative.

Still, developing the contents to be covered in 
Figure 1

Expressing Milk Game Interfaces produced for nurses working in agribusiness companies, 2020.

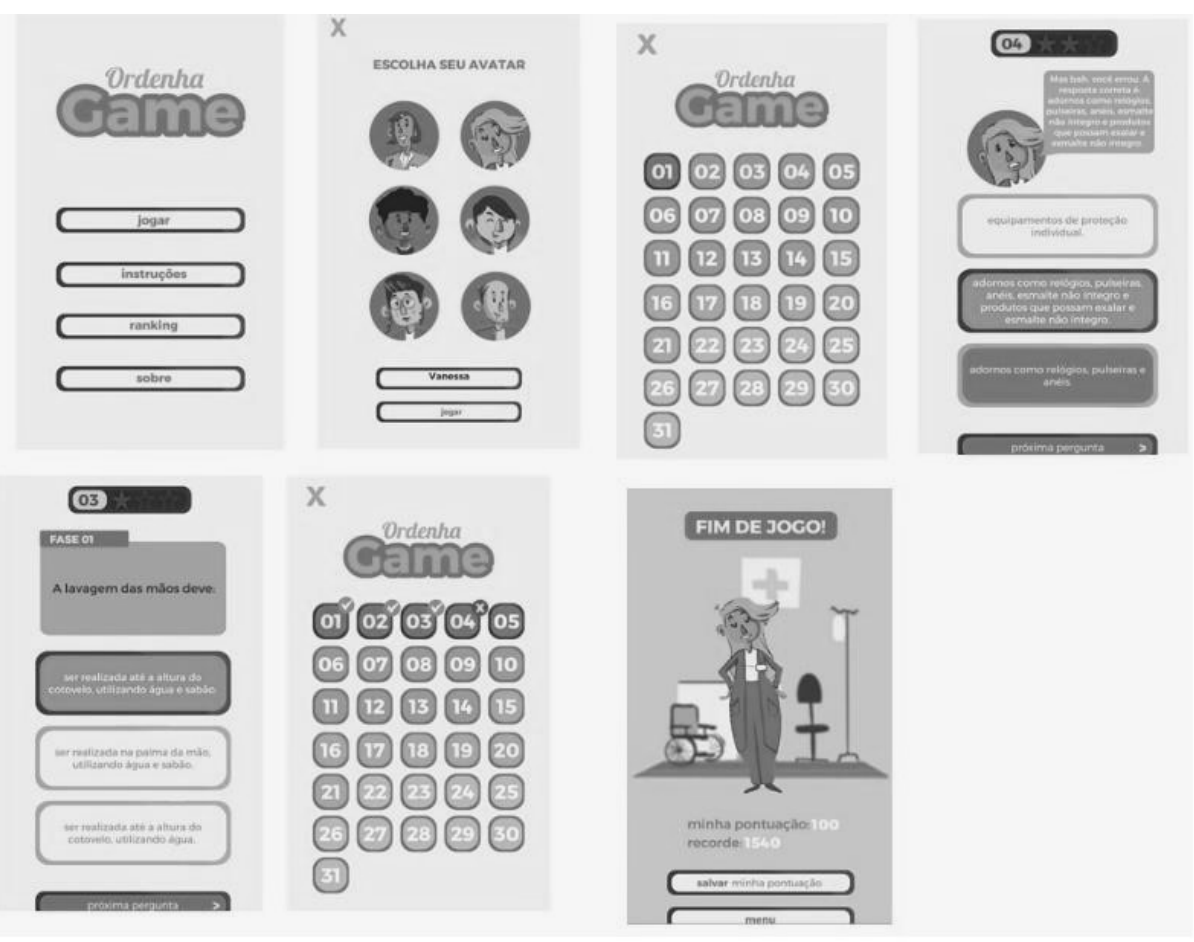

Table 3

Presentation of the scores of the occupational nurses' assessment regarding the usability of the Expressing Milk Game, 2020.

\begin{tabular}{|c|c|c|c|c|c|c|c|c|c|}
\hline \multirow[t]{2}{*}{ Questions SUS } & \multicolumn{9}{|c|}{ Nurses } \\
\hline & Nur 1 & Nur 2 & Nur 3 & Nur 4 & Nur 5 & Nur 6 & Nur 7 & Nur 8 & Nur 9 \\
\hline \multicolumn{10}{|l|}{ 1- I think I would like to use } \\
\hline this product often & 3 & 3 & 4 & 3 & 4 & 4 & 4 & 3 & 4 \\
\hline \multicolumn{10}{|l|}{ 2-I consider the product more } \\
\hline complex than necessary & 2 & 2 & 4 & 3 & 4 & 3 & 2 & 3 & 4 \\
\hline \multicolumn{10}{|l|}{ 3-I think the product is easy } \\
\hline to use & 3 & 4 & 3 & 3 & 4 & 4 & 4 & 3 & 4 \\
\hline \multicolumn{10}{|l|}{ 4- I think I will need help from } \\
\hline this product & 3 & 4 & 3 & 4 & 4 & 4 & 4 & 3 & 4 \\
\hline \multicolumn{10}{|l|}{ 5- I consider the various features } \\
\hline \multicolumn{10}{|l|}{ 6-I think this product has many } \\
\hline inconsistencies & 3 & 3 & 4 & 3 & 4 & 4 & 3 & 3 & 4 \\
\hline \multicolumn{10}{|l|}{ 7- I suppose most people will learn } \\
\hline to use this product quickly & 2 & 4 & 4 & 3 & 4 & 3 & 3 & 4 & 0 \\
\hline
\end{tabular}

* System Usability Scale (SUS) instrument, BROOKE, 1996, translated by Padrini-Andrade, et al.11 
Presentation of the scores of the occupational nurses' assessment regarding the usability of the Expressing Milk Game, 2020.

\begin{tabular}{|c|c|c|c|c|c|c|c|c|c|}
\hline \multirow[t]{2}{*}{ Questions SUS } & \multicolumn{8}{|c|}{ Nurses } & \multirow[b]{2}{*}{ Nur 9} \\
\hline & Nur 1 & Nur 2 & Nur 3 & Nur 4 & Nur 5 & Nur 6 & Nur 7 & Nur 8 & \\
\hline \multicolumn{10}{|l|}{ 8- I consider this product too } \\
\hline complicated to use & 2 & 4 & 4 & 3 & 4 & 4 & 4 & 4 & 4 \\
\hline \multicolumn{10}{|l|}{ 9- I felt very confident using } \\
\hline this product & 2 & 3 & 4 & 3 & 4 & 4 & 3 & 3 & 0 \\
\hline \multicolumn{10}{|l|}{ 10- I had to learn a lot before } \\
\hline I could handle this product & 1 & 3 & 4 & 3 & 4 & 3 & 4 & 3 & 4 \\
\hline Summing questions & 25 & 33 & 37 & 31 & 40 & 37 & 35 & 32 & 32 \\
\hline Result SUS* \% & $62.50 \%$ & $82.50 \%$ & $92.50 \%$ & $77.50 \%$ & $100.00 \%$ & $92.50 \%$ & $87.50 \%$ & $80.00 \%$ & $80.00 \%$ \\
\hline Classification & Good & Excellent & $\begin{array}{c}\text { Best } \\
\text { possible }\end{array}$ & Excellent & $\begin{array}{c}\text { Best } \\
\text { possible }\end{array}$ & $\begin{array}{c}\text { Best } \\
\text { possible }\end{array}$ & $\begin{array}{c}\text { Best } \\
\text { possible }\end{array}$ & Excellent & Excellent \\
\hline
\end{tabular}

* System Usability Scale (SUS) instrument, BROOKE, 1996, translated by Padrini-Andrade, et al.11

Table 4

Final mean assessment of health nurses at work about improving their knowledge on Expressing Milk Game, 2020.

Criteria on Knowledge Improvement Category -EGameFlow

Final mean

1- Does the game improve my knowledge?

2- Do I understand the basic ideas of the content presented?

3- Do I try to apply the knowledge in the game?

4- Does the game motivate the player to integrate the presented content?

5- Do I want to know more about the presented content?

* EGameFlow instrument, Improving Knowledge category (Tsuda et al.14)

applications requires skill from the researcher, since a transformation of knowledge is required, and the product needs to be instructive, interesting and coherent. ${ }^{17}$ In the midst of the technology era, it is challenging to propose a relevant product for the healthcare field.

As for usability, the Expressing Milk Game was rated as excellent. It is believed that this opinion is associated with the development process, which involved professionals from health, informatics and graphic design, and this broad interdisciplinary look was extremely important for the development and improvement of the game. The contributions made by multidisciplinary teams are essential in the development of technologies, as they enrich the process with technical knowledge. 19

Occupational nurses certified the Expressing Milk Game as a technology that improves know- ledge, since in the final assessment reached an excellent score, similar to a study that also validated the improvement of knowledge through games. 20

Studies that applied this educational methodology highlight positive ratings, as it motivates users, making them interested in the content.21,22 From the moment a person has the experience with a Serious Game, they clearly perceive its relevance in relation to traditional teaching and learning methodologies. 20 Thus, it is believed that this technology contributes to the care provided to the health of nursing mothers.

The use of games is considered a trend in professional training. They are able to stimulate engagement through living experiences. So, it is possible to predict that this is an innovative teaching and learning strategy that has conquered space in the educational sphere. 23 This way, it is essential that its 
use be encouraged in education, especially when it comes to professionals' training/qualification in the working field. 24

It appears that the use of educational technologies by health professionals is a reality, as they increasingly use smartphones in clinical practice. 25 In this study, it was evidenced that the Serious Game technology enables the training/qualification of health professionals who are nursing mothers, promoting the continuity of breastfeeding after the mothers return to work. In addition to training professionals, it is essential that companies promote knowledge about the importance of breastfeeding at the workplace. 26

This research allowed the description of the stages in developing and validating an educational technology from the Serious Game type about expressing breast milk by nursing mothers. The methodology proved to be able to support the development and validation of the Expressing Milk Game, as a contribution to the experts and the target audience that made it possible to detect the necessary changes to be made to qualify this educational health technology.

It is noteworthy that, for the educational script to have credibility and reliability, it is extremely important that the stage of construction of the content is based on scientific evidence. Therefore, it is essential to carry out a search on the topic in databases of indexed journals, as well as the use of protocols from recognized organizations and association in the health field. And also to highlight the importance of the process of validation content by professionals in the area who have, in addition, to technical-scientific knowledge, the knowledge arising from the practice in daily care.

The development of a technology of the Serious Game type demands time and commitment from the team, since many meetings and dialogues among members are required. However, this interdisciplinary process provides the improvement of the professionals involved, as there is an exchange of knowledge between the areas of health, computer science and graphic design.

Although the Expressing Milk Game is relevant as a potential learning technology for health professionals who work in industries and need to guide nursing mothers after returning to work to continue breastfeeding, its development had some limitations. The main limiting factor was not having been tested and evaluated by a larger number of health professionals who work in the healthcare for nursing mothers.

Finally, the importance of the attractive and motivating educational technologies is stressed. They are innovating and improving health education processes, enhancing training and making it attractive. From this perspective, due to the natural competitive appeal of games, Serious Games prove to be a fruitful educational strategy.

\section{Acknowledgement}

We would like to thank the University scholarship program in Santa Catarina - UNIEDU, supported by the Manutenção e ao Desenvolvimento da Educação Superior - FUMDES (Support Fund for the Maintenance and Development of Higher Education) - for granting the scholarship for the last twelve months of the course; and the occupational nurses who carried out the validation of the Serious Game; and the agribusiness company for supporting and implementing the developed product.

\section{Authors' contribution}

Moraes VC: preparation of the initial project, bibliographic reference search, data collection, statistical analysis, preliminary version of the article. Ferraz L: guidance for carrying out the research, critical intellectual review of the manuscript. All the authors approved the final version of the article. 


\section{References}

1. Rollins NC, Lutter CK, Bhandari N, HajeebhoyN, HortonS Martines JC, et al. Por que investir e o que será necessário para melhorar as práticas de amamentação. Epidemiol Serv Saúde. 2016; 25 (1): 25-44.

2. Victoria GC, Bahl R, Barros AJD, França GVA, Horton S, Krasevec J, et al.Breastfeeding in the 21st century: epidemiology, mechanisms, and lifelong effect. Lancet. 2016; 387 (10017): 475-90.

3. WHO (World Health Organization). Guideline: protecting, promoting and supporting breastfeeding in facilities providing maternity and newborn services. Geneva; 2017.

4. Fernandes VMB, Santos EKA, Zampieri MFM, Gregório VRP, Hernandes MJ, Ribeiro LC. Manager's condutrelated to the breastfeeding support at the workplace. Texto Contexto Enferm. 2018; 27 (3): e2560016.

5. Oliveira CS, Iocca FA, Carrijo MLR, Garcia RATM Breastfeeding and complications that contribute to early weaning. Rev Gaúcha Enferm. 2015; 36 (spe): 16-23.

6. Santos CA, Souza-Junior VD, Lanza FF, Lacerda AJ Mendes IAC.Serious games in virtual environments for health teaching and learning. Rev Rene. 2017; 18 (5): 7029.

7. Lewis ZH, Swartz MC, Lyons EJ. What's the point?: a review of reward systems implemented in gamification interventions. Games Health J. 2016; 5 (2): 93-9.

8. Polit DF, Beck CT.Fundamentos de pesquisa em enfermagem: avaliação de evidências para a prática da enfermagem. 7 ed. Porto Alegre: ArtMed; 2011.

9. Alexandre NMC, Coluci MZO. Content validity in the development and adaptation processes of measurement instruments. Ciênc Saúde Coletiva. 2011; 16 (7): 3061-8.

10. Novak J.Desenvolvimento degames. 2 ed. São Paulo: Cengage Learning; 2010.

11. Padrini-Andrade L, Balda RCX,Areco KCN, BandieraPaiva P, Nunes MV, Marba STM, et al. Evaluation of usability of a neonatal health information system according to the user's perception. Rev Paul Pediatr. 2018; 37 (1): 906

12. Bangor A, Kortum P, Miller J. Determining what individual SUS scores mean: adding an adjective rating scale. J Usability Stud. 2009; 4 (3): 114-23.

13. Brooke J. SUS: a quickanddirtyusabilityscale. In: Jordan PW, Thomas B, McClelland IL, Weerdmeester B, editors. Usability evaluation in industry. London: Taylor \& Francis; 1996. p. 189-95.

Received on September 14, 2020

Final version presented on April 15, 2021

Approved on July 14, 2021
14. Tsuda M, Sanches VM, Ferreira TG, Otsuka JL, Beder DM. Análise de métodos de avaliação de jogos educacionais. In: Anais XIII SBGames; 12-14 nov 2014; Porto Alegre, PR. Porto Alegre, PR: Sociedade Brasileira de Computação; 2014. p. $158-66$.

15. Benevides JL, Coutinho JFV, Pascoal LC, Joventino ES, Martins MC, Gubert FA, et al. Development and validation of educational technology for venous ulcer care. Rev Esc Enferm USP. 2016; 50 (2): 309-16

16. Tenório APS. Construção e validação de um website sobre cuidados com prematuro [tese]. Recife: Centro de Ciências da Saúde da Universidade Federal de Pernambuco; 2016.

17. Toneti BF. Desenvolvimento e validação de tecnologias digitais voltadas ao ensino de uma prática integrativa e complementar em saúde [tese]. Ribeirão Preto: Escola de Enfermagem de Ribeirão, Universidade de São Paulo; 2019.

18. Oelke ND, Lima MADS, Acosta AM. Knowledge translation: translating research into policy and practice.Rev Gaúcha Enferm. 2015; 36 (3): 113-7.

19. Pinto TRC, Castro DS, Bringuente MEO, Sant'Anna HC, Souza TV, Primo CC. Educational animation about home care with premature newborn infants. Rev Bras Enferm. 2018; 71 (Suppl 4): 1604-10.

20. Domingues NA, Tibes CM, Dias JD, Westin UM, ZemMascarenhas SH, Fonseca LMM. Virtual simulation by computer on nursing teaching: experience report. Rev Enferm UFPI. 2017; 6: 70-4

21. Fonseca LMM, Aredes ND, Dias DMV, Scochi CGS, Martins JCA, Rodrigues MA. Serious game e-Baby: percepción de estudiantes de enfermería sobre elaprendizaje de evaluación clinica del prematuro. Rev Bras Enferm. 2015; 68 (1):13-9.

22. Deguirmendjian SC, Miranda FM, Zem-Mascarenhas SH.Serious game desenvolvidos na Saúde: revisão integrativa da literatura. J Health Inform. 2016; 8: 110-6.

23. Castro TC, Gonçalves LS. The use of gamifi cation to teach in the nursing field. Rev Bras Enferm. 2018; 71 (3): 103845

24. Giunti G, Baum A, Giunta D, Plazzotta F, Benitez S, Gómez A, et al.Serious games: a concise overview on what they are and their potential applications to healthcare. Stud Health Technol Inform. 2015; 216: 386-90.

25. Grabowsky A. Smartphone use to answer clinical questions: a descriptive study of APNs. Med Ref Serv Q. 2015; 34 (2): $135-48$.

26. Khaliq A, Qamar M, Hussaini SA, Azam K, Zehra N, Hussain M, et al. Assessment of knowledge and practices about breastfeeding and weaning among working and nonworking mothers. J Pak Med Assoc. 2017; 67 (3): 332-8. 